\title{
Multi-criteria Model with a Fuzzy Hierarchical Analysis Process - FAHP, for the Selection of Providers in a Cellular Mobile Telecommunications Company in Colombia
}

\author{
MSc. Leydy J. Hernández Viveros ${ }^{1 *}$ MSc. Jennifer C. Murcia Rodriguez ${ }^{2}$ and PhD. Danilo A. López Sarmiento ${ }^{3}$ \\ ${ }^{1}$ Corporación Universitaria Minuto de Dios - UNIMINUTO, Faculty of Engineering, Bogotá, Colombia, South America, \\ ${ }^{2}$ Corporación Universitaria Minuto de Dios - UNIMINUTO, Faculty of Engineering, Bogotá, Colombia, South America, \\ ${ }^{3}$ Universidad Distrital Francisco José de Caldas, Faculty of Engineering, Bogotá, Colombia, South America,
}

ORCID:000-0002-1688-8775 (First Author), ORCID: 0000-0002-5724-6657 (Second Author)

ORCID: 0000-0002-8814-0600 (Third Author)

\begin{abstract}
This article seeks to establish the main basis for the selection of the best provider for a company in the cellular mobile telecommunications sector in Colombia, based on a multicriteria model to find the correct and most adequate prediction, depending on their particular conditions for each one of the companies. The model achieved a combination of the multi-criteria tools Hierarchical Analytical Process (AHP) and Fuzzy Hierarchical Analytical Process (FAHP), for the selection of a supplier of telecommunications equipment for a company in the same sector, considering a group of critical factors to evaluate a Possible solution of the best and most suitable alternative, which allowed us to offer a solution to telecommunications companies according to their specific needs. The methodology used is descriptive, and its approach was mixed (quantitative and qualitative), which begins with a sufficient thematic review of the two tools, passing through the gathering of information with the application of a technical research instrument (survey) to identify the selection criteria that companies have and finally designing the fuzzy multicriteria model. The results are based on the contributions provided by the model developed for the selection of suppliers, making its application viable, for companies that wish to choose to link the FAHP methodology to companies, concluding that it is an easy model adaptability for decisionmaking, showing that the selection of any type of criterion is taking more and more force, allowing companies to be at the forefront of technology.
\end{abstract}

Keywords: Model, Multicriteria, Selection, FAHP.

\section{INTRODUCTION.}

The selection of suppliers is a multicriteria decision-making problem because it involves both subjective particularities and internal processes within companies for their selection, for example, there are tenders, fair competition, among others; particularities based on qualitative and quantitative characteristics, which makes it necessary to apply multi-criteria tools to solve it. This research achieves the interaction between two methodologies or tools that facilitate decision making, leaving aside particular and individual subjectivity, depending on personal convenience to be a legitimate and reliable process when making decisions according to business needs. Suppliers are a very important part of the supply chain of all companies, since they depend on the strengthening of supply management and are a fundamental part of the good development and performance of supply, a real situation of great interest to all those related companies in this field of study. Suppliers, in turn, are of great help to comply with those required by end customers, for whom the internal suppliers of companies are transparent, but which implies the good or bad image that companies leave with the end customer. At the same time, having alliances that allow business growth is what companies in the whole sector are looking for today, strengthening relationships between competitors and suppliers.

Within the article a methodology based on the design is proposed in the application of a combination of the multicriteria tools Hierarchical Analytical Process (AHP) and Diffuse Hierarchical Analytical Process (FAHP), for the selection of a supplier of telecommunications equipment in Colombia, providing in this way to business, technological and economic growth, supporting medium and small companies in the cellular mobile telecommunications sector in Colombia, allowing them to be within the constant evolution of technology.

\section{RELATED STUDIES}

Some studies prior to the development of the model are based on the bibliographical investigation of the application in other areas of the multicriteria methodologies, Hierarchical Analytical Process (AHP) and Diffuse Hierarchical Analytical Process (FAHP), which founded the research.

In relation to the above, the authors [1] conclude in the study that out of 78 articles published between 2000 and 2008, own approaches are more used than integrated approaches, with 
Data Envelopment Analysis (DEA) being the most used, followed by mathematical programming and the AHP model. The AHP model is the most widely used hierarchical analysis process for multicriteria decision making, as indicated in its article [2].

Similarly, the authors [3] conducted a review of provider selection methods in 49 articles from 1992 to 2007, grouping them into: 1) mathematical programming models, 2) linear weighting models, and 3) statistical / probabilistic approaches, concluding that the AHP method is the most used among the linear weighting models. It is from this method that the history of researchers, companies or industrial sectors that study this process is born, as happens with the authors [4], where they use the AHP and ANP methodologies to compare four strategic work options for a management unit. 250 hectares' private forest. Using these two tools, they make a comparison of the results where they discuss the differences, as well as the strengths and weaknesses of both approaches.

The same happens with the authors [5], who design a multiattribute model for application in the agricultural sector based on the AHP method for the selection of agricultural machinery. For his part [6] presents a multi-criteria methodology for a company dedicated to the provision of health services in order to implement an $\mathrm{ABC}$ costing system and by using the AHP technique seeks to prioritize processes.

It is in this way, that it is possible to appreciate that the AHP process is a useful, practical and systematic method for the selection of suppliers [7]. However, in practice, open data is sometimes inadequate to design a real-life situation [8], since human judgments are vague and cannot be represented with exact numbers [9]; For this reason, the AHP methodology with triangular fuzzy numbers is used to represent the comparison of judgments in decision-making, as expressed by the authors focused on a washing machine company [10]. Fuzzy set theory is similar to human reasoning in the use of approximate information and in the uncertainty generated by decisions and offers the advantage of mathematically representing such uncertainty and vagueness, providing formalized tools to deal with the intrinsic imprecision of many problems [ eleven].

In this way, the use under other modalities or applications within the tools that are used in the investigation is evidenced, however, there is evidence of a knowledge gap regarding the application in the selection of providers for companies in the cellular mobile telecommunications sector.

\section{RESULTS}

The multicriteria model was designed based on three fundamental pillars for its development: According to the preprocessing of the supplier selection with modeling of the appropriate criteria, to the prediction of the selection criteria of suppliers of cellular mobile telecommunications equipment and to the post-processing selection of cellular mobile telecommunications equipment provider [12].

\subsection{Model Description}

The members belonging to the purchasing committee or, in effect, to the commercial ones, were selected as a group of experts, since they are the ones who directly intervene in the supplier selection process, considering that they are in charge of choosing the possible candidates and evaluate their performance, authorize and make purchases and payments, make quotations, as well as decide who, when and how much to buy.

The execution of the model was carried out through a software called MATLAB-MathWorks-Simulink exported to a template in Microsoft Excel®, as this is a practical and functional tool that allows the mathematical development required by the technique, in addition to facilitating the understanding of the operations carried out and their results.

AHP is used to calculate the weights of the criteria and the total weights of the alternatives for each criterion; and then fuzzy logic is used to evaluate the selection problem and obtain the suggested result.

As mentioned above, there is a selection of criteria, which are given a weight in letter and number for greater ease of handling, as expressed in Table 1.

Table 1. Decision criteria

\begin{tabular}{|cc|}
\hline & CRITERIA \\
\hline $\mathrm{C} 1$ & Quality \\
$\mathrm{C} 2$ & Price \\
$\mathrm{C} 3$ & Compliance \\
$\mathrm{C} 4$ & After Sales \\
$\mathrm{C} 5$ & Company \\
\hline
\end{tabular}

It is considered for this project to have 3 alternatives which are simulated to be 3 suppliers of the companies, which are given a weight in letters by the alphabet of A - C, as shown in Table 2 .

Table 1. Alternatives to Evaluate

\begin{tabular}{|lr|}
\hline & ALTERNATIVES \\
\hline A & Provider 1 \\
B & Provider 2 \\
C & Provider 3 \\
\hline
\end{tabular}

In the hierarchy that was provided to the model, 3 levels are used:

- Level 1: Located at the top. There the main objective or goal of the problem is defined.

- Level 2: Located in the middle. It is made up of multiple criteria, with their sub-criteria that define the alternatives.

- $\quad$ Level 3: Located at the bottom. Made up of competing alternatives. 
Then, the comparison by pairs of criteria was established, to construct said matrix of comparison by pairs, the nine-point scale of Satty was used. The weights assigned to each matrix were obtained as a result of the consensus of the group of experts, that is, it comes from each one of the surveys carried out on cellular mobile telecommunications companies. The decision matrix for the quality criterion is therefore the following:

Table 2. Comparison matrix of alternatives for criterion $\mathrm{C} 1$.

\begin{tabular}{l|l|l|l|} 
C1 & \multicolumn{1}{l}{ A } & \multicolumn{1}{l}{ B } & \multicolumn{1}{l}{ C } \\
A & 1,0000 & 1,0000 & 0,1429 \\
B & 1,0000 & 1,0000 & 0,1429 \\
C & 7,0000 & 7,0000 & 1,0000 \\
\cline { 2 - 4 } & &
\end{tabular}

Source: Own elaboration, extracted from the software by Excel.

Where:

$\mathrm{B}$ is equally preferred as $\mathrm{A}$

$\mathrm{C}$ is very strongly preferred than A

$\mathrm{C}$ is very strongly preferred than $\mathrm{B}$

In addition, the reciprocal value is obtained for each comparison pair.

To calculate the normalized decision matrix, divide each term of the decision matrix by the sum of its corresponding column.

The standardized matrix for the quality criterion is therefore the following:

Table 3. Normalized decision matrix of the alternatives for criterion $\mathrm{C} 1$

\begin{tabular}{c|c|c|c|}
\multicolumn{1}{c}{ C1 } & \multicolumn{1}{c}{$\mathrm{A}$} & \multicolumn{1}{c}{$\mathrm{B}$} & \multicolumn{1}{c}{$\mathrm{C}$} \\
\cline { 2 - 4 } $\mathrm{A}$ & 0,1111 & 0,1111 & 0,1111 \\
\cline { 2 - 4 } $\mathrm{B}$ & 0,1111 & 0,1111 & 0,1111 \\
\cline { 2 - 4 } $\mathrm{C}$ & 0,7778 & 0,7778 & 0,7778 \\
\hline
\end{tabular}

Source: Own elaboration, extracted from the software by Excel.

The priority vector is calculated, which is obtained by calculating the average of each row of the normalized matrix.

The priority vector for the quality criterion is therefore the following:

Table 4. Priority vector of the alternatives for criterion $\mathrm{C} 1$

\begin{tabular}{|ll|}
\hline C1 & \\
\hline A & 0,1111 \\
B & 0,1111 \\
C & 0,7778 \\
\hline
\end{tabular}

Source: Own elaboration, extracted from the software by Excel.
The consistency coefficient is calculated, to calculate this coefficient, called (CC), you must first find some values, for which the following formulas are used, which are programmed from the software:

$$
\begin{aligned}
V_{i} & =A * W_{i} \\
\lambda_{i} & =\frac{V_{i}}{W_{i}} \\
I C & =\frac{\left(\lambda_{\text {Max }}-n\right)}{n-1}
\end{aligned}
$$

Where:

$\mathrm{A}=$ is the comparison matrix in Table 3 .

$\mathrm{Vi}=$ is the weighted sum, of the values in the row of the decision matrix for alternative $i$, with the weight corresponding to that alternative $\mathrm{i}$.

$\mathrm{IC}=$ is the consistency index.

$\lambda \_$Max $=$is the average of the $\mathrm{i}$

In addition, it is necessary to know the Random Index (IA) which was found with the following formula:

$$
I A=\frac{1,98 *(n-2)}{n}
$$

Finally, the formula to find the consistency coefficient is applied:

$$
C C=\frac{I C}{I A}(5)
$$

In this way, the consistency coefficient for the quality criterion can be seen in Table 6 .

Table 5. Consistency result of the matrix of alternatives for criterion $\mathrm{C} 1$.

\begin{tabular}{|ccc|}
\hline Alternativa & $\mathrm{V}$ & $\lambda$ \\
\hline A & 0,3333 & 3,0000 \\
B & 0,3333 & 3,0000 \\
C & 2,3333 & 3,0000 \\
\hline & & \\
\hline & $\lambda \mathrm{MAX}$ & 3,0000 \\
\hline IC & IA & $\mathrm{CC}$ \\
0,0000 & 2,9700 & 0,0000 \\
\hline
\end{tabular}

Source: Own elaboration, extracted from the software by Excel.

Under these data, the literature on the formulas indicates that if the $\mathrm{CC}$ is less than or equal to the allowable value of 0.10 , the consistency of the decision matrix is within an acceptable 
tolerance. But if the consistency ratio is greater than 0.10 the matrix is said to be inconsistent, then subjective judgments should be reviewed and the process repeated.

Taking into account the above, the decision matrix analyzed is consistent because it is within the allowable tolerance range.

The fuzzy technique is the next step for the actual process used to be the Fuzzy Hierarchical Analysis Process - FAHP, and to achieve this step it is necessary to keep the above information in mind.

Table 7 shows the weights associated with the priority vector of the criteria matrix and the matrices for each alternative for each criterion.

Table 6. Decision matrix to apply fuzzy technique.

\begin{tabular}{cccccc|} 
Alternative & C1 & C2 & C3 & C4 & C5 \\
A & 0,111 & 0,096 & 0,750 & 0,078 & 0,777 \\
B & 0,111 & 0,284 & 0,125 & 0,688 & 0,155 \\
C & 0,778 & 0,619 & 0,125 & 0,234 & 0,069 \\
Weights (W) & 0,023 & 0,031 & 0,031 & 0,034 & 0,024 \\
\hline
\end{tabular}

Source: Own elaboration, extracted from the software by Excel.

Then the positive and negative ideal solution must be determined, the positive ideal solution will be the highest value associated with each criterion:

Table 7. Values of the positive $(\mathrm{A}+)$ and negative (A-) ideal solution for each criterion

$\begin{array}{cccccc} & \text { C1 } & \text { C2 } & \text { C3 } & \text { C4 } & \text { C5 } \\ \text { A } & 0,022 & 0,028 & 0,030 & 0,032 & 0,023 \\ \text { B } & 0,003 & 0,004 & 0,005 & 0,004 & 0,002\end{array}$

Source: Own elaboration, extracted from the software by Excel.

Finally, the proximity of the alternatives with respect to the ideal solution is calculated and each one is assigned a priority value.

The following formula is used to calculate how close the alternatives are to the ideal solution:

$$
C^{*}=\frac{D^{-}}{D^{+}+D^{-}} ; 0<C_{i}^{*}<1
$$

Where:

$\mathrm{C} *=$ the proximity of the alternatives with respect to the ideal solution.
After obtaining the value of $\mathrm{C} *$ for each of the alternatives, we proceed to order them depending on their priority.

Table 9 shows the proximity values obtained for each alternative and the priority of each one.

Table 8. Results and prioritization of alternatives.

\begin{tabular}{|c|c|c|}
\hline Alternativa & Resultado & Prioridad \\
\hline A & 0,1855 & 3 \\
\hline B & 0,6701 & 2 \\
\hline C & 0,3705 & 1 \\
\hline
\end{tabular}

Source: Own elaboration, extracted from the software by Excel.

\section{DISCUSSION}

As can be seen in Table 9, which represents the results obtained from the application of the methodology, it is evident that the appropriate or suggested alternative, that is, the one that best meets the criteria considered by cellular mobile telecommunications companies, is option $\mathrm{B}$ with a value of 0.6701 of preference (option that is closer to the positive ideal solution $\mathrm{A}+$ and farther from the negative ideal solution A-); therefore, it is suggested to the companies that when applying the design bear this development in mind so that they select the supplier according to these criteria mentioned above. As a second option, it is suggested to select alternative $\mathrm{C}$ because it obtained a result of 0.3705 with respect to the other options. On the other hand, the least favorable alternative is supplier A with 0.1855 .

\section{CONCLUSIONS}

It is concluded within this article that it was possible to combine the subjective judgments of the group of experts (Account or commercial managers) for the criteria and the alternatives, with the applied methodology (AHP combination - fuzzy logic), which allowed to offer a solution to the telecommunications companies according to their real specific needs, since the mathematical formulation or modeling is easy to use from the same Excel, without the software, allowing in this way to provide satisfaction and continuous improvement in supplier management. In this way, it was possible to define each of the criteria that were located within a survey so that the same companies that select suppliers gave objective answers, being able to analyze the main criteria that involve the selection of suppliers and manage to locate them within the development of the model. .

The multicriteria decision model used can be used not only for the selection of suppliers but also in any field where decisions are required, in which various qualitative and quantitative decision factors and different alternative solutions intervene. In addition, it is presented as a friendly tool that can be performed on spreadsheets complemented by the good management of MATLAB-MathWorks-Simulink software. 
Finally, when talking only about the AHP methodology, an uncertainty is created that is presented by the judgments made by the experts regarding the value given to the criteria among themselves and the alternatives with criteria, it is necessary to indicate that this was mitigated with the use of the fuzzy logic technique to reduce this concern.

\section{REFERENCES}

[1] W. Ho, X. Xiaowei y D. Prasanta, «Multi-criteria decision making approaches for supplier evaluation and selection,» European Journal of Operational Research, pp. 16-24, 2010.

[2] J. Osorio y P. Orejuela, «EL PROCESO DE ANÁLISIS JERÁRQUICO (AHP) Y LA TOMA DE DECISIONES MULTICRITERIO. EJEMPLO DE APLICACIÓN.,» Scientia Et Technica. XIV (39), pp. 247 - 252, 2008.

[3] A. Deshmukh y A. Chaudhari, «A Review for Supplier Selection Criteria and Methods,» Technology Management \& Engineering, pp. 283 - 291, 2011.

[4] W. Bernhard, V. Harald y J. Manfred, «Application of the analytic network process in multi-criteria,» University of Natural Resources and Applied Life Sciences, p. 82, 2005.

[5] J. Garcia, S. Noriega, J. Diaz y J. Riva, «Aplicación del proceso de jerarquía analítica en la selección de tecnología agrícola,» Agronomía Costarricense30, pp. 107-114, 2006.

[6] V. Jimenez, «Aplicación de metodología multicriterio para la priorización de los procesos objeto de costeo en entidades del sector de la salud,» Libre Empresa , pp. 99$123,2012$.

[7] A. Zouggari y L. Benyoucef, «Simulation based fuzzy TOPSIS approach for group multi-criteria supplier selection problem,» Engineering Applications of Artificial Intelligence, p. 111, 2016.

[8] A. Genovese y R. Passaro, «AHP-based approaches for supplier evaluation: Problems and perspectives,» Journal of Purchasing \& Supply Management, p. 159, 2012.

[9] G. Bruno y E. Esposito, «Applying supplier selection methodologies in a multi-stakeholder,» Expert Systems With Applications, pp. 271 - 283, 2016.

[10] O. Kilincci y S. Aisli, «Fuzzy AHP approach for supplier selection in a washing machine company,» Expert Systems with Applications, pp. 9656-9664, 2011.

[11] W. Ho, T. He, C. Lee y A. Emrouznejad, «Strategic logistics outsourcing: An integrated QFD and fuzzy AHP approach,» Expert Systems with Applications, pp. 1084110850, 2012.

[12] L. Hernández, O. Salcedo y D. López, «Proposal for a Management Model for SME Providers using a MultiCriteria Model with a Fuzzy Analytical Hierarchy Process - FAHP,» International Journal of Engineering Research and Technology, vol. 12, n 12 , pp. 2834-2838, 2019. 